\title{
Bridging Students Multicultural Competency Across Institutions: A Model of Practice
}

\author{
Meredith Drew ${ }^{1} \&$ Kristin Vincenzes ${ }^{2}$ \\ ${ }^{1}$ College of Education, William Paterson University, Wayne, NJ, USA \\ 2 The Stephen Poorman College of Business, Information Systems, and Human Services, Lock Haven University, \\ Lock Haven, PA, USA \\ Correspondence: Merdith Drew, College of Education, William Paterson Unversity, Wayne, NJ, 07470 USA. Tel: \\ 1-973-720-3092.
}

Received: February 9, 2018

doi:10.5430/irhe.v3n2p1
Accepted: February 27, 2018

Online Published: April 3, 2018

URL: https://doi.org/10.5430/irhe.v3n2p1

\begin{abstract}
This model was created between two institutions to provide opportunities for graduate counselor trainees to experience and work with more culturally diverse clients/students. All students were enrolled in Clinical Interviewing/Advanced Skills courses and were required to complete two counseling transcripts. Students completed a brief survey identifying their cultural identity. The instructors used this information to pair students from diverse cultures. Students then engaged in four counseling sessions (each student was in the role of counselor and client twice) via a synchronous technology platform. Students wrote a transcript of the counseling session along with a case conceptualization and analysis of their counseling skills.
\end{abstract}

Keywords: multicultural, online, counselor trainees, skills

The United States of America is said to be the melting pot of the world. While diversity is all around us, some students, particularly from small rural towns, do not have an array of multicultural experiences nor knowledge. As counselor educators, we continuously strive to teach students cultural competency, recognizing that there are certain attitudes and beliefs that are connected to multicultural competence which counselors must commit to practicing (Ratts, Singh, Nassar-McMillan, Butler, \& McCullough, 2016). While educators can infuse the didactic learning opportunities throughout the counseling curriculum, the challenge becomes trying to provide experiential learning opportunities for trainees to practice their knowledge with diverse clients. In order to be multiculturally competent, counselors must be immersed in their community, cognizant of their strengths and limitations, seek relevant resources, be self-reflective, use critical thinking, and seek opportunities for developing (Ratts et al., 2016). There are times when our students do not have the ability to seek these opportunities and as counselor educators, it is the responsibility of the program to help develop their multicultural competence. The next question that comes to mind is how are we evaluating our students' knowledge and skills on multicultural counseling?

Often times, counselor trainees are supervised by someone who shares a similar culture and works with clients from similar cultural backgrounds. Due to the lack of exposure to different cultures, it is difficult to determine if counselor trainees are actually competent in this area. As Sue and Sue (2013) have discussed thoroughly, it is essential for counselor trainees/students to become competent in the area of multicultural awareness. The responsibility of this training falls on the shoulders of the academic program. In a study by Drew (2013), 62 participants were asked to what degree would they consider their counselor's culture to be different then their own. Results indicated that $24.2 \%(\mathrm{~N}=31)$ stated the cultures were very alike, minimally different, or not all. The same participants rated themselves as culturally competent when working with their clients (Drew, 2013). The question arises, "How can students be culturally competent when they do not have experience providing counseling services to people who are culturally diverse?" Furthermore, "How can counselor education programs infuse more opportunities for trainees to gain this experience?"

\section{Multicultural Competency}

The American Counseling Association Code of Ethics (2014) focuses on awareness of different cultures and counselors remaining unbiased when working with clients. Furthermore, the Council for Accreditation of Counseling 
and Related Educational Programs (CACREP, 2016) continues to value and require programs to embed multicultural competencies into their curriculum. Castillo, Brossar, Reyes, Conoley, and Phoummarath (2007) found that first year counselor trainees' cultural self-awareness, knowledge and skills increased after students took a course in the multicultural counseling. Chao, Wei, Good, and Flores (2011) focused specifically on racial discrepancies for multicultural awareness and found that although white counseling students' multicultural awareness increased with additional training, students from racial-ethnic minorities' multicultural awareness was not impacted. These results lend itself to the possibility that counselor educators may need to prepare students to be multiculturally competent by using different approaches depending on the trainee's racial-ethnic background (Chao, 2013).

Dickson and Shumway (2011) discussed the importance of multicultural competency requiring a multi-faceted approach. Didactic learning is not enough to provide students with the competency needed, rather trainees need experiential opportunities to further build upon the foundational knowledge acquired through books. Many programs require an experiential component to their multicultural counseling course that helps broaden and challenge students' knowledge on a particular population. Often times, this activity requires students to step out of their comfort level and engross themselves within a cultural population that is different than their own. While this activity is extremely beneficial to start breaking down personal biases and thoughts regarding different populations, programs also need to be active in providing clinical opportunities for students to use their counseling and conceptualization skills with culturally diverse clients. Counselor educators need to be creative with how to further develop these important skills in our students.

\section{Purpose}

Multicultural awareness, knowledge, and skills are key components to any counselor and especially important for counselor trainees. As counselor educators, it is our responsibility and commitment to provide opportunities for our students to gain multicultural competency. Sometimes educators are unable to provide a diverse student body to enable students to gain this experience; however, we need to look at other opportunities to meet the needs of our students. By collaborating with our colleagues at other institutions, we may be able to provide students with a diverse counseling experience as they continue to practice their basic clinical skills and move forward in the field of counseling. This is an opportunity to ensure that we developing the skills of our counselor trainees and opening opportunities for diverse clinical experience. One way for counselor education programs to be actively involved in expanding students' knowledge and experience is by explicitly providing these opportunities. The purpose of this study was to introduce an experiential model that was created between two institutions to provide opportunities for graduate counselor trainees to work with more culturally diverse clients/students. This model was a pilot study and could be expanded in the future to encompass entire counseling skills courses at separate universities. Specifically, this study looked to examine the question of would counseling across institutions increase a counselor trainees' multicultural competence? The hypothesis states that the counseling sessions with someone from a different university would increase the students' multicultural awareness as assessed by the MCKAS scale (Ho: $\mu 1=\mu 2$ and Ha: $\mu 1 \neq \mu 2)$.

\section{Research Methodology}

The study used a quasi-experimental design. This design was chosen to determine if there was a change in the participant's multicultural competence and skills after working with clients from different institutions, but all participants/groups participated in the counseling sessions. Groups were equivalent by ability, gender, age range, and requirement of the counseling sessions. By comparing the participant's level of skills before the counseling sessions and then again after the sessions, we are able to see if there was a change in competence with participants.

Inclusion criteria consisted of students currently enrolled in a counseling skills course at the time of the study. Students were matriculated into counselor education programs. The study hypothesized there would be a change in the participants' scores on the Multicultural Counseling Knowledge and Awareness Scale (MCKAS) in both the knowledge scale and awareness scale after completing these counseling sessions with participants from different academic institutions.

\subsection{Participants}

Participants in the current study were students enrolled in counselor education program at either a small rural university in Central Pennsylvania or a larger university in Northern New Jersey. This study followed volunteer purposive sampling, as participants were volunteers, yet a specific course was targeted due to the clinical skill requirement. All participants who were enrolled in the clinical interviewing/advanced counseling skills courses within their programs received a survey request. Participants that wanted to participate in the study, completed the 
survey request. If students were interested in participating in the study, students selected a link that discussed the informed consent. If the student continued to the demographics questionnaire, then consent was assumed. Out of the 30 students who were emailed, initially, there were eight participants $(N=8)$ who volunteered. As the study progressed, one participant did not respond to attempts to schedule counseling sessions; therefore, the sample size was reduced to six, in order to have even pairs for the clinical counseling sessions. The six participants were all female and ranged in age from 23 years old to 26 years old, with a mode of 26 years old. Additionally, participants identified as five Caucasian and one bi-cultural.

\subsection{Method}

The six students who participated in this experiential model were partnered together with a student from the other university. Students completed initial demographic questionnaire and the Multicultural Counseling Knowledge and Awareness Scale (MCKAS). The MCKAS is a two-factor instrument that includes 20 Knowledge items and 12 Awareness items extracted from the original 45-item MCKAS. The MCKAS measures participant's knowledge regarding multicultural concepts and kills and awareness of Eurocentric worldview biases that the participant may hold (Lu, 2017). The two-factor model has been supported in both exploratory factor analysis and confirmatory factor analysis of the MCKAS. Research on the MCKAS across multiple samples has shown the two factors to be internally consistent. Coefficient alphas for the Knowledge scale have clustered in the .92 range; and for the Awareness scale in the .78 range (Ponterotto \& Potere, 2003). The MCKAS has a total of 32 items and is rated on a Likert scale of one (not at all true) to seven (totally true).

Students who completed both the demographic questionnaire and the initial MCKAS were paired up between the schools. The researchers reviewed the demographic questionnaires and attempted to pair up the students who self-identified with different cultural backgrounds. For example, researchers paired a student who identified as white with a student who identified as bi-cultural. Since the two universities were geographically located in different states, the counseling role-plays occurred via Blackboard Collaborate. This synchronous technology was chosen because it was the teaching platform used in the one university's online program. Blackboard Collaborate allows for synchronous audio and visual tools for live counseling sessions with the protection of confidentiality. In order to maintain confidentiality of the information shared in the role-plays, faculty deleted the recordings. This ensured that their sessions could not be accessed by anyone else after the study was completed.

Students engaged in four counseling sessions (each student was in the role of counselor and client twice). Each counseling session was 50 minutes in length to simulate the length of an actual session with a client. Following each session, students composed a transcript of the session. After both sessions were completed, the student's completed a case conceptualization and analysis of their counseling skills. In addition, participants took the MCKAS survey again.

\section{Data Analysis}

Dependent t-tests were used to analyze the data in order to determine if there was a change in reported multicultural competence skills measured by the MCKAS after the counseling sessions. Participants scored themselves on the MCKAS prior to participating in the counseling role-plays. After all four sessions concluded, the same participants retook the MCKAS. This analysis helped determine if participating in the counseling sessions with students from another university impacted the participants' personal perspectives on their multicultural competency and whether there was a change in skill perception from prior to the counseling session experience and then to after. Therefore, we measured the difference in MCKAS scores from initial score to final score after the study participation was completed.

\section{Results}

Initially, there were a total of four participants from each university that completed the survey and questionnaire. As the process progressed to arranging for counseling session times, one participant from one university did not respond. Therefore, the sample size was reduced to three participants at each university resulting in three pairs. Dependent t-tests were used to analyze the data provided by participants after completing the MCKAS. Participants completed the MCKAS prior to the counseling sessions and then again after participating in the four counseling sessions (two sessions were led by each student).

The knowledge scale has a range of 20 to 140 reflecting statements of multicultural knowledge. Prior to the students participating in the distance multicultural counseling mock sessions, the knowledge scale results ranged from 76-117 $(M=97.67, S E=14.65)$. The post-test results ranged from 80-117 ( $M=61, S E=13.87)$. In addition, the awareness scale 
has a range of 12-84 and reflects statements of potential worldview biases. The results ranged from a pre-test of 39-71 $(M=61, S E=13.87)$ and a post-test range of 49-71 $(M=63.83, S E=8.59)$.

On average, students did not report a significant difference $(t=0.976, p=0.346)$ in their multicultural knowledge base after the counseling sessions $(M=100.67, S E=6.31)$ as compared to their multicultural knowledge base prior to the counseling sessions $(M=97.67, S E=5.98)$; however, the quasi experimental condition yielded a significantly large correlation coefficient $(\mathrm{r}=.869, p=.025)$. Therefore, we accept the null hypothesis, which stated that the counseling sessions with someone from a different university did not impact the students' multicultural awareness as assessed by the MCKAS scale.

On average, students did not report a significant difference $(t=1.202, p=0.249)$ in their multicultural awareness after the counseling sessions $(M=63.83, S E=3.51)$; as compared to their multicultural awareness prior to the counseling sessions $(M=61 S E=5.66)$; however, the experimental condition yielded a significantly large correlation coefficient $(\mathrm{r}=.846, p=.034)$. Therefore, we do not reject the null hypothesis, which stated that the counseling sessions with someone from a different university did not impact the students' multicultural awareness as assessed by the MCKAS scale.

\section{Limitations}

One of the limitations when analyzing the results of this study is to consider the very small sample size and the lack of diversity within the sample. There were only six female students who volunteered to be in the study and all six females were similar in age (range 23-26) and race (five identified as Caucasian and one identified as bi-racial); therefore, significantly limiting the generalizability of the results. Even with the small sample size, the increase in self-reported multicultural awareness and skills supports the intention of the study to expose students to multicultural experiences with clients. Furthermore, since the cultural demographics were not very diverse, it could have impacted the validity of the results. One recommendation is to do the study again, but expand the opportunity to all students in both programs rather than limiting the study to the students currently taking the skills course in each program. Another recommendation may be to include a larger participant pool by working with more than two different institutions to further increase the potential to recruit more participants as well as increase the potential for diversity within those participants.

Another limitation may be in the number of mock counseling sessions the participants experienced. Perhaps four mock counseling sessions (two as the "counselor" and two as the "client") is not sufficient to impact the post-test results. One recommendation may be for the participants to participate in more sessions to be between five and seven in order to mirror a brief solution-focused approach. This way the participants can experience the entire counseling process from intake, implementation of solution-focused brief therapy, and the termination process. To further this concept, if this study is duplicated again with a larger sample size, participants could be assigned to the diverse counseling sessions or limited to no diversity in the counseling sessions and then compare the results of the MCKAS to determine if there is a difference in the participation of the diverse counseling session and participant assessment of their clinical counseling skills.

\section{Discussion}

As the United States continues to increase in its' population diversity, multicultural competency for clinicians will become even more essential. Unfortunately, the student population in many counseling programs may not have the cultural diversity representative in the population at large. This discrepancy is even more noticeable in small rural campuses; therefore, it is important for counselor educators in these programs to develop new and innovative strategies to expose their students to more diversity. The goal of this study was to do an experimental design in order to assess if participation in mock counseling sessions with students from another university across state borders would impact the students' multicultural knowledge and awareness as assessed by the MCKAS scale. The results from this study did not find significant differences between before and after MCKAS assessment scales; however, additional analysis found that there was a large positive correlation between the pre and post test results. This may be due to students feeling more competent the more they engaged in counseling sessions and practiced their skills with clients who are unfamiliar to them.

\section{Conclusion}

While the current study did not illustrate significant results, this research can spike interest and creative thinking to help spur additional research in the area of multicultural competency (to include knowledge, awareness, and skills). As counselor educators, we need to be proactive in helping our students to gain this crucial experience. While programs try to recruit and retain a diverse cultural student body per the CACREP (2016) standards, unfortunately 
small rural campuses have a much more difficult time doing this; therefore, these programs need to think outside of the box to help their students gain the experience of working with diverse clients. Perhaps by counseling programs working together and collaborating on these efforts, we can provide the students with increased opportunities to gain the knowledge, awareness, and skills to become competent, comfortable, and confident to provide counseling services to a more diverse clientele.

\section{References}

Ahmed, S., Wilson, K. B., Henriksen, Jr., R. C., \& Jones, J. W. (2011). What does it mean to be a culturally-competent counselor?. Journal for Social Action in Counseling and Psychology, 3(1), 17-28.

American Counseling Association. (2014). Code of Ethics. Alexandria, VA: American Counseling Association.

Castillo, L. G., Brossar, B. F., Reyes, C. J., Conoley, C. W., \& Phoummarath, M. J. (2007). The influence of multicultural training on perceived multicultural counseling competencies and implicit racial prejudice. Journal of Multicultural Counseling and Development, 35, 243-254. https://doi.org/10.1002/j.2161-1912.2007.tb00064.x

Chao, R. C. (2013). Race/ethnicity and multicultural competence among school counselors' multicultural training, racial/ethnic identity, and color-blind attitudes. Journal of Counseling \& Development, 91, 140-151. https://doi.org/10.1002/j.1556-6676.2013.00082.x

Chao, R. C., Wei, M., Good, G. E., \& Flores, L. Y. (2011). Race/ethnicity, color-blind racial attitudes, and multicultural competence: The moderating effects of multicultural counseling training. Journal of Counseling Psychology, 58, 72-82. https://doi.org/10.1037/a0022091

Council for Accreditation of Counseling and Related Educational Programs. (2016). CACREP Accreditation Manual. Alexandria, VA: Author.

Dickson, G. L., \& Shumway, B. A. (2011). A framework of multi-faceted approaches to multicultural training. Retrieved from http://counselingoutfitters.com/vista/vista11/Article_69pdf

Drew, M. (2013). The relationship of personal counseling to the development of new counselors. Unpublished doctoral dissertation, Walden University, Minnesota.

Larson, L. M., Suzuki, L. A., Gillespie, K. N., Potenza, M. T., Bechtel, M. A., \& Toulouse, A. L. (1992). Development and validation of the Counseling Self-Estimate Inventory. Journal of Counseling Psychology, 39(1), 105-120. https://doi.org/10.1037//0022-0167.39.1.105

Lu, J. (2017). Multicultural counseling knowledge and awareness scale: Re-exploration and refinement. International Journal for Advancement of Counselling, 39(1), 14-27. https://doi.org/10.1007/s10447-016-9279-2

Ponterotto, J. G., \& Potere, J. C. (2003). The Multicultural Counseling Knowledge and Awareness Scale (MCKAS): Validity, reliability, and user guidelines. In D. P. Pope-Davis, H. L. K. Coleman, W. M. Liu, \& R. Toporek (Eds.), Handbook of multicultural competencies in counseling and psychology (pp. 137-153). Thousand Oaks, CA: Sage. https://doi.org/10.4135/9781452231693.n9

Ponterotto, J. G., \& Ruckdeschel, D. E. (2007). An overview of coefficient alpha and a reliability matrix for estimating adequacy of internal consistency coefficients with psychological research measures. Perceptual and Motor Skills, 105, 997-1014. https://doi.org/10.2466/pms.105.3.997-1014

Ponterotto, J. G., Utsey, S. O., \& Pedersen, P. B. (2006). Preventing prejudice: A guide for counselors, educators, and parents (2nd ed.). Thousand Oaks, CA: Sage.

Ratts, J., Singh, A. A., Nassar-McMillan, S., Butler, S. K., \& McCullough, J. R. (2016). Multicultural and social justice counseling competencies: Guidelines for the counseling profession. Journal of Multicultural Counseling and Development, 44(1), 28-48. https://doi.org/10.1002/jmcd.12035

Sue, D. W., \& Sue, D. (2013). Counseling the culturally different: Theory and practice (6th ed.). New York, NY: Wiley Publishers. 